\title{
sciendo
}

\section{Less Than One Millimeter Under the Great Toe is Enough to Change Balance Ability in Elite Women Handball Players}

\author{
by \\ Frederic Viseux ${ }^{1,2,3}$, Franck Barbier ${ }^{1}$, Rodolfo Parreira ${ }^{3,4}$, Antoine Lemaire ${ }^{2}$, \\ Philippe Villeneuve ${ }^{1,3}$, Sebastien Leteneur ${ }^{1}$
}

Team handball is a complex intermittent sport game, which requires several motor abilities and effective postural control. Objective evaluation of stabilometric variables may be interesting to assess and improve functional parameters by postural control management. The purpose of the study was to evaluate the effects of a small additional thickness placed under the great toe (TUGT) on the Centre of Pressure (CoP) parameters in elite women handball players. Fourteen elite women handball players voluntarily participated in this study. Two conditions were compared: TUGT 0 (control) and TUGT $0.8 \mathrm{~mm}$; four variables were computed from the CoP displacements. A paired T-test was performed for each variable. This study concludes that a low focal additional thickness placed under both great toes has an effect on the CoP measures used to assess postural control during an unperturbed stance. These results suggest that a low TUGT could contribute to a change in balance ability, and may be of clinical interest. This brings new perspectives in the management of athletes to prevent injury risk and optimize performance.

Key words: postural insoles, balance ability, toes.

\section{Introduction}

Balance performance has a fundamental role in many athletic activities, and skill in postural control may determine a successful performance (Adlerton et al., 2003; Maszczyk et al., 2018). The ability to minimize postural sway can be defined as postural performance (Paillard et al., 2006), and may be evaluated in a stable state or following a specific perturbation (Gerbino et al., 2007). Athletes usually have superior balance ability compared to non-athletes (Davlin, 2004) and athletes at the highest level of competition have more stable posture than those at the lower level (Paillard and Noe, 2006). Even if the importanceof balance to sport activities may appear apparent, its relationship with performance and motor abilities has not been proven (Hrysomallis, 2011). On the other hand, deficits in static and dynamic balance have been discussed as important intrinsic risk factors of sustaining lower extremity injuries (Dallinga et al., 2012; Witchalls et al., 2012).

Handball is a complex intermittent sport game, which requires several motors abilities such as sprinting or jumping, to drive physical actions based on flexibility and throwing velocity (Gorostiaga et al., 2006). These abilities contribute to the high performance of a team (Granados et al., 2007; Marques and Gonzalez-Badillo, 2006) and require static and dynamic control of balance. It is important to note that maintenance of good

\footnotetext{
1 - UMR CNRS 8201, Laboratoire d'Automatique, de Mécanique et d'Informatique industrielles et Humaine (LAMIH) Université polytechnique des Hauts-de-France (UPHF), F-59313 Valenciennes, France.

2 - Centre d'évaluation et de traitement de la douleur (CETD), centre hospitalier de Valenciennes (CHV), F-59322 Valenciennes,

France.

3 - Posture Lab, F-75012 Paris, France.

4 - Residence program in manipulative, complementary and integrative physical therapy - Salgado Institute of Integral Health/UniFil, Londrina, PR - Brazil.
} 
postural control depends upon continual integration of sensory inputs from visual, vestibular, and somatosensory receptors (i.e., proprioceptors and mechanoreceptors) by the central nervous system which will assess the body position and the movement (Patel et al., 2009). It refers to stances and being in the correct position for each technique executed and demands on strength, flexibility and sensory motor awareness (Vijayaragavan and Perumal, 2016). For instance, in the game of handball, a player has to either pass or receive the ball, which could occur while a player is static or in motion. In this circumstance, the player needs to maintain their posture over the base of the support without swaying. Several clinical and laboratory methods have been developed to assess different dimensions of balance in order to assist clinical decision-making with respect to interventions for balance-related deficits. The most prevalent test for static balance consists of recording the Centre of Pressure (CoP) displacements (Palmieri et al., 2002; Raymackers et al., 2005). These recordings can be made according to specified duration as a subject attempts to stand motionless on a force plate, in a unipedal or a bipedal stance, with eyes open or closed (Asseman et al., 2008; Paillard et al, 2002). Minimal CoP displacements are indicative of good balance and the $\mathrm{CoP}$ measured from a force plate is generally considered the gold standard measure of balance (Clark et al., 2010). Although there is some evidence on an association between greater postural sway and increased risk of injuries (Mc Guine et al., 2000; Soderman et al., 2001; Wang et al., 2006), many questions remain in relation to the negative influence of impaired balance on sport performance (Zemkova, 2014). Though this may be true for shooting (Ball et al., 2003; Mononen et al., 2007) or archery (Balasubramaniam et al., 2000), findings have shown that in many other sports, highly skilled athletes are able to perform successfully in spite of increased postural sway (Zemkova, 2014). Objective evaluation of stabilometric variables may be interesting to assess and consider functional parameters by the management of postural control according to the characteristics of sport activities.

The human foot is the direct interface between the body and the ground during practice, and could be considered as a sensory structure that provides somatosensory feedback and contributes to balance control (Kavounoudias et al., 1998, 2001) and posture awareness (Roll et al., 2002). The increased distribution of cutaneous afferents in the toes compared with the heel (Inglis et al., 2002; Stzralkowski et al., 2018) may reflect the postural significance of feedback from the toes in regard to the control of standing balance (Inglis et al., 2002; Stzralkowski et al., 2018; Wright et al., 2012; Viseux et al., 2018). In fact, the toes play a unique and important role in standing balance (Okay and Kohn, 2015; Tortolero et al., 2008; Tanaka et al., 1996a, 1996b; Viseux et al., 2018). For example, a low focal additional thickness placed under the toes showed a change in stabilometric parameters of the CoP (Viseux et al., 2018). Therefore, the purpose of the present study was to evaluate the effects of a low additional thickness placed only under the great toe on the $\mathrm{CoP}$ measures in elite women handball players. On the assumption that mechanoreceptors are activated by moderate mechanical stimuli (Viseux et al., 2019), it was hypothesized that static balance ability would change with the low focal additional thickness used to compute these measures.

\section{Methods}

\section{Participants}

Fourteen elite women handball players voluntarily participated in this study. They gave their informed consent to the experimental procedure as required by the Declaration of Helsinki and the university (UPHF) review board. Toe deformity and orthopedic or neurological disorders which could influence postural control were exclusion criteria. Skin sensitivity to pressure was evaluated on the toes using a monofilament Semmens-Weinstein 5.07 (Apelqvist et al., 2000). The monofilament was applied perpendicularly under each toe until they were bent for approximately $2 \mathrm{~s}$. Participants were instructed to provide confirmation each time they felt the monofilament under their toes. When participants failed to sense the monofilament after its bending, they were excluded from this study.

\section{Design and Procedures}

Postural oscillations were recorded for each participant using a force plate (AFP / APE85, $40 \mathrm{~Hz} / 16$-bit, Win-posturo®, Médicapteurs $\odot$, France) and analyzed with software (v; 1.8, Winposturo $\left.{ }^{\circledR}\right)$ coupled to the force plate. Participants stood upright on the platform, with lowered arms, 
barefoot, with heels $2 \mathrm{~cm}$ apart and feet away at $30^{\circ}$. Data were collected with a sampling frequency of $40 \mathrm{~Hz}$ over $51.2 \mathrm{~s}$. The foot position was marked on the platform and repeated for both conditions. The average of three consecutive measurements was recorded. The participant's task was to stand as still as possible during the trial. Two randomized conditions were compared: additional thicknesses under the great toe (TUGT), $0 \mathrm{~mm}$ (control) and $0.8 \mathrm{~mm}$. TUGT were made of rigid polyester resin and with an ovular form. They had a width of $28 \mathrm{~mm}$ and a length of $35 \mathrm{~mm}$. The hardness was 60 Shore $\mathrm{A}$, and the density was 250 $\mathrm{kg} / \mathrm{m}^{3}$. TUGT were placed under the plantar surface of the great toe of both feet. There was no time to adapt to different conditions. In order to avoid the phenomenon of habituation of the plantar cutaneous mechanoreceptors, a twominute period of seated rest separated each recording (Forth and Layne, 2007). Under each condition, four variables were computed from the CoP displacements: (i) the surface of CoP excursions; (ii) the frontal $(\mathrm{X})$ mean position of the
$\mathrm{CoP}$; (iii) the sagittal ( $\mathrm{Y}$ ) mean position of the $\mathrm{CoP}$, and; (iv) the mean speed of the CoP.

Note that these CoP measures are widely employed in clinical practice to assess individual's postural control capacities during an unperturbed stance (Raymakers et al., 2005).

\section{Statistical analysis}

Statistical analysis was performed using SPSS statistics software. A paired T-test was performed for each variable (Table 1) since the Shapiro-Wilk test revealed a normal distribution of the data. For all analyses, the threshold of significance was set at $p<0.05$.

\section{Results}

As shown in Figure 1, a difference with TUGT 0.8 compared to control condition was observed for two of the four variables: the surface of CoP excursions and the average speed of the CoP. No difference was observed for the sagittal $(\mathrm{Y})$ and the frontal $(\mathrm{X})$ mean position of the CoP.

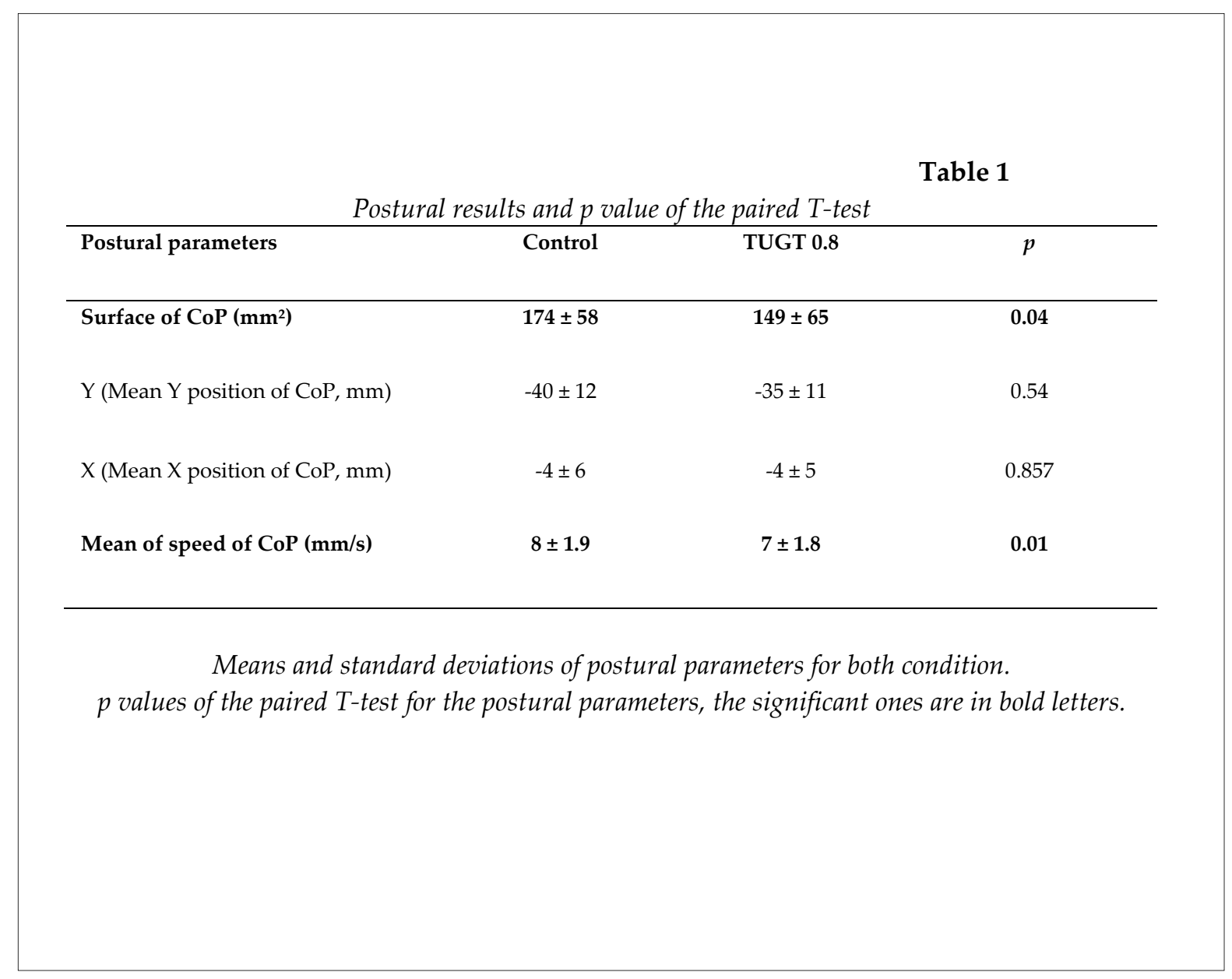




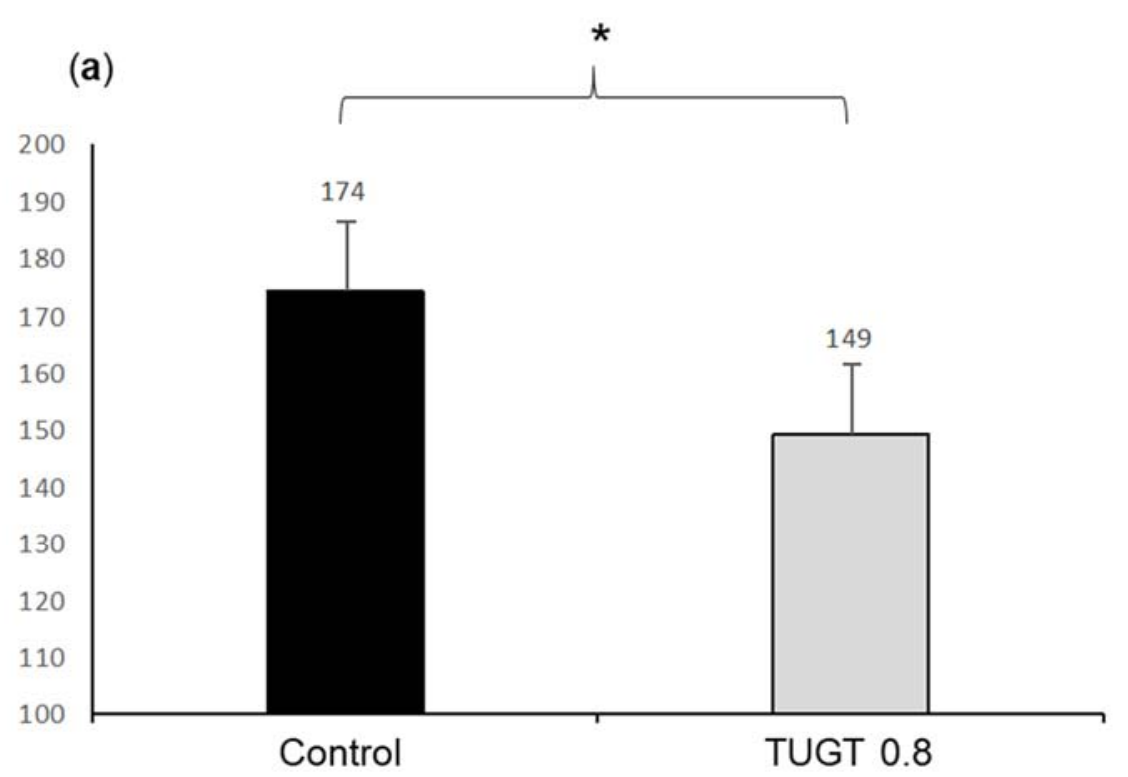

(b)

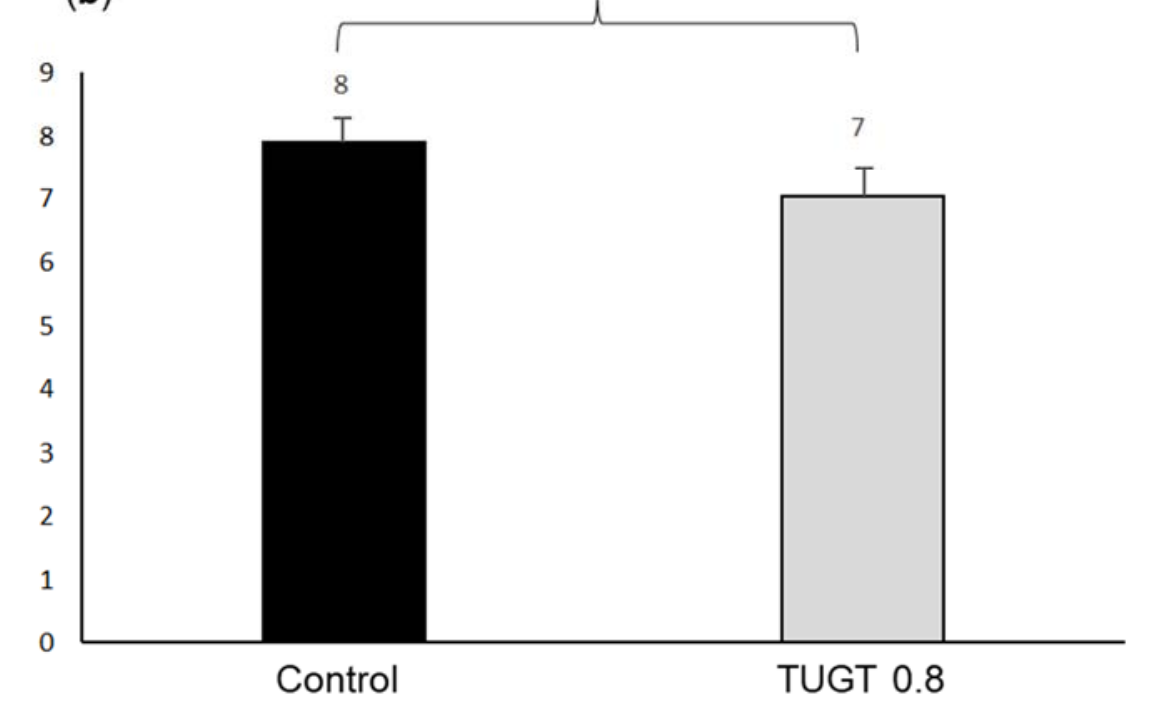

Figure 1 (a) Area of the $\mathrm{CoP}\left(\mathrm{mm}^{2}\right)$ for all conditions

Error bars represent the standard error. The * denotes a statistically significant difference with $p<0.05$. CoP: Centre of Pressure, Control: Control condition $(0 \mathrm{~mm})$, TUGT: Thickness Under Great Toes $(0.8 \mathrm{~mm})$. (b) Average speed of the CoP $(\mathrm{mm} / \mathrm{s})$

for all conditions. Error bars represent the standard error. The ${ }^{* *}$ denotes a statistically significant difference with $p=0.01$. CoP: Centre of Pressure, Control:

Control condition $(0 \mathrm{~mm})$, TUGT: Thickness Under Great Toes $(0.8 \mathrm{~mm})$. 


\section{Discussion}

This study provides evidence that a low focal additional thickness placed under both great toes has an effect on the CoP measures used to assess static balance ability during an unperturbed stance. Our results suggest that a very small additional thickness is sufficient to change CoP measures. These postural reactions are consistent with previous reports that used mechanical stimulation of the plantar sole (Viseux et al., 2018, 2019), and could assist in changing the balance ability in athletes. Balance can be defined statically as the ability to maintain a base of support with minimal movement, and dynamically as the ability to perform a task while maintaining a stable position (Winter et al., 1990). Athletes generally have superior balance ability compared to nonathletes (Davlin, 2004). The ability to maintain static or dynamic balance is likely to be linked to a specific task and possibly not a general trait (Hrysomallis, 2011). For instance, gymnasts have superior dynamic balance to soccer players and swimmers (Davlin, 2004), and superior static balance to basketball players (Bressel et al., 2007). This ability is influenced by a complexity of factors, which include sensory information, joint range of motion and strength (Palmieri et al., 2002, 2003), stature and body mass (Davlin, 2004), playing positions (Wagner et al., 2014), training experience (Balter et al, 2004) or levels of performance (Paillard et al., 2006; Paillard and Noe, 2006). Since balance ability is fundamental for the correct execution of complex sport movements, as well as for protection against injuries, it seems interesting to be able to optimize it. Some authors have carried out prospective assessments of athletes in order to determine how stabilometric changes can be a causal factor for injuries (Mc Guine et al., 2000; Soderman et al., 2001; Wang et al., 2006). McGuine et al. (2000) assessed the first two weeks of the season for basketball players, and correctly described balance as a predictor of injuries, showing that those with higher postural sway values at the start of the season were the ones most injured in the long term. Similar results were found by Wang et al. (2006) who established a correlation between poor mediolateral stability and suffering from ankle injuries later on. Also, Soderman et al. (2001) correlated all lower extremity injuries with increases in postural sway in female soccer players. Furthermore, at shooting practice during handball, static balance is important and postural sway needs to be controlled (Karadenizli et al., 2014). Studies showed that bipedal static balance while throwing was associated with shooting accuracy for elite and novice rifle shooters (Ball et al., 2003; Mononen et al., 2007). Therefore, improving static balance could optimize performance during handball practice, especially when throwing. Research therefore suggests that changes in both sensory and motor systems influence balance performance (Ricotti, 2011).

Inappropriate or defective information from any of the sensory systems (i.e., visual, vestibular, and somatosensory receptors) can result in instability due to a mismatch between incoming sensory signals (Bloem et al., 2002). Thus, the CNS has to compensate this mismatched information from sensory receptors to correctly functioning receptors where, according to Pyykko et al. (1990), the most important source of somatosensory information comes from plantar mechanoreceptors, being the most important site when balance is perturbed (Stal et al., 2003). In this way, the addition of a small thickness under the toes facilitated the tactile cutaneous sensation and reduced the individual's postural sway (Viseux et al., 2018). In fact, plantar cutaneous afferents play a role in stabilizing the feet, providing an additional source of sensory input that enhances the detection of movement and controlling smallamplitude body sway (Kavounoudias et al., 1998, 1999). More particularly, some studies have suggested the role of toes in postural control (Okay and Kohn, 2015; Tanaka et al., 1996a, 1996b; Tortolero et al., 2008; Viseux et al., 2018). In order to maintain balance, toes are used to correct for postural disturbance. The toes provide a stable surface area that remains in contact with the ground and serve to relay relevant sensory information to the central nervous system $(\mathrm{Ku}$ et al., 2012). Some authors (Okay and Kohn, 2015; Tortolero et al., 2008) showed that the toe muscle stimulation was capable of regulating CoP displacements, and may be a good candidate for controlling balance. In those studies, forward movement of the CoP was induced by different intensity of electrical stimulation applied to the toe muscles. Furthermore, body acceleration could be controlled during quiet standing by regulating the intensity of stimulation applied to the toe muscles (Tortolero et al., 2008). One of the explanations 
given by the authors was that the contracted toe muscles increased the tactile sensation at the toe, which indirectly induced the cutaneous afferent activity (Tortolero et al., 2008). This hypothesis agrees with Kavounoudias et al. (1999) who showed that vibration to the sole of the foot behind the toes induced a soleus activity at the latency of $0.119 \pm 0.028 \mathrm{~s}$, which generated a small forward movement of the CoP at the latency of $0.251 \pm 0.111$ $\mathrm{s}$ followed by the CoP backward movement with the latency of $0.9 \pm 0.4 \mathrm{~s}$. Recently, Viseux et al. (2018) showed evidence that a small focal additional thickness placed under the toes had an effect on the CoP measures used to assess postural control during an unperturbed stance. More largely, a significant change of balance was obtained with the lowest thickness $(0.8 \mathrm{~mm})$, even though the contact forces induced by the lowest thickness were probably too small to mechanically stabilize the body.

In this context, our results suggest that cutaneous mechanoreceptors of the great toe were activated by a low focal additional thickness and seem to be consistent with a tactile hypothesis of Tortolero et al. (2008). These sensory signals are used to perform postural corrections when balance disturbances occur (Tortolero et al., 2008). Their use can improve balance ability (Abbruzzese et al., 1996; Schieppati et al., 1994; Tortolero et al., 2008) and could play an interesting role in optimizing performance and preventing injury in sports. As a clinical application, inclusion of specific plantar cutaneous feedback facilitation of athletes could be recommended in order to improve stabilometric parameters and decrease and/or eliminate their role as risk factors.

There are potential limitations when interpreting the observations reported in this paper. First, although this study showed significant effects of low cutaneous mechanical stimulation placed under both great toes on static balance, it would be necessary to consider these effects on dynamic balance. Indeed, dynamic balance is considered more challenging because it requires the ability to maintain equilibrium during a transition from a dynamic to a static state (Ross and Guskiewiez, 2004). Effective dynamic balance is necessary in the fundamental technical movements of handball such as dribbling. Handball players require consistent balance as they run at high speeds, change direction and powerfully throw the ball to pass or shoot (Rannou et al., 2001). Second, different factors that affect static and dynamic balance such as anthropometric characteristics and motor abilities (Salehzadeh et al., 2011), proprioceptive balance and visual clues (Gioftsidou et al., 2012), strengthening programs (Martins et al., 2019), or training experience (Paillard et al., 2006) should be considered. Third, since the relationship between balance ability and sport injury risk has been established (Hrysomallis, 2011), it would be interesting to consider a longitudinal evaluation of these parameters and to correlate them with the occurrence of injuries during the season.

Finally, because the study was conducted with such a specialized group of athletes, sample size was relatively small. A multicenter trial involving elite handball women players from different teams may be a good alternative.

In conclusion, cutaneous information arising from the great toes plays an important role in controlling posture. The assumption that a low focal additional thickness under the great toe may change static balance is supported by the results of the present study. However, future investigations will have to be considered in order to understand the neurophysiological mechanisms underlying these postural reactions. A small additional thickness (less than $1 \mathrm{~mm}$ ) under the great toe could change balance control, even if these modifications are transient. It would be interesting to carry out a longitudinal assessment of these effects. Objective evaluation of stabilometric variables is interesting to improve functional parameters by postural rehabilitation according to the characteristics of sport activities. Thus, the application of focal additional tactile cues may have therapeutic benefits in relation to the development of novel clinical practice to improve balance. This way of facilitating the sensory feedback of plantar receptors is quite simple and it is possible to insert a low additional thickness into a customized sole. In this context, this brings perspectives in the management of athletes to prevent injury risk and optimize performance. 


\section{References}

Abbruzzese M, Rubino V, Schieppati M. Task-dependent effects evoked by foot muscle afferents on leg muscle activity in humans. Electroencephalogr Clin Neurophysiol, 1996; 101: 339-48

Adlerton AK, Moritz U, Moe-Nilssen R. Force plate and accelerometer measures for evaluating the effect of muscle fatigue on postural control during one-legged stance. Physiother Res Int, 2003; 8: 187-99

Apelqvist J, Bakker K, Van Houtum WH, Nabuurs-Franssen MH, Schaper NC. International consensus and practical guidelines on the management and the prevention of the diabetic foot. International working group on the diabetic foot. Diabetes Metab Res Rev, 2000; 16: S84-92

Asseman FB, Caron O, Crémieux J. Are there specific conditions for which expertise in gymnastics could have an effect on postural control and performance? Gait Posture, 2008; 27: 76-81

Balasubramaniam R, Riley MA, Turvey MT. specificity of postural sway to the demands of a precision task. Gait Posture, 2000; 11: 12-24

Ball KA, Best RJ, Wrigley TV. Body sway, aim point fluctuation and performance in rifle shooters: inter and intra-individuals analysis. J Sports Sci, 2003; 21: 559-66

Balter SGT, Stokroos RJ, Akkermans E, Kingma H. Habituation to galvanic vestibular stimulation for analysis of postural control abilities in gymnasts. Neurosci Lett, 2004; 366: 71-75

Bloem BR, Allum JH, Carpenter MG, Verschuuren JJ, Honegger F. Triggering of balance corrections and compensatory strategies in a patient with total leg proprioceptive loss. Exp Brain Res, 2002; 142: 91-107

Bressel E, Yonker JC, Kras J, Health EM. Comparison of static and dynamic balance in female collegiate soccer, basketball, and gymnastics athletes. J Athl Train, 2007; 42: 42-6

Chou SW, Cheng HY, Chen JH, Ju YY, Lin YC, Wong MK. The role of the great toe in balance performance. J Orthop Res, 2009; 27: 549-54

Clark RA, Bryant AL, Pua Y, McCrory P, Bennell K, Hunt M. Validity and reliability of the Nintendo Wii board for assessment of standing balance. Gait Posture, 2010; 31: 307-10

Dallinga JM, Benjaminse A, Lemmink KA. Which screening tools can predict injury to the lower extremities in team sports? a systematic review. Sports Med, 2012; 42: 791-815

Davlin CD. Dynamic balance in high level athletes. Percept Mot Skills, 2004; 98: 1171-6

Forth KE, Layne CS. Background muscle activity enhances the neuromuscular response to mechanical foot stimulation. Am J Phys Med Rehabil, 2007; 86: 50-66

Gerbino PG, Griffin ED, Zurakowski D. Comparison of standing balance between female collegiate dancers and soccer players. Gait Posture, 2007; 26: 501-7

Gioftsidou A, Malliou P, Sofokleous P, Pafis G, Beneka A, Godolias G. The effects of balance training on balance ability in handball players. Exe Qual life, 2012; 4: 15-22

Gorostiaga EM, Granados C, Ibanez J, Gonzalez-Badillo JJ, Izquierdo M. Effects of an entire season on physical fitness changes in elite male handball players. Med Sci Sports Exerc, 2006; 38: 357-66

Granados C, Izquierdo M, Ibanez J, Bonnabau H, Gorostiaga EM. Differences in physical fitness and throwing velocity among elite and amateur female handball players. Int J Sports Med, 2007; 28: 860-7

Hrysomallis C. Balance ability and athletic performance. Sport Med, 2011; 41: 221-32

Inglis JT, Kennedy PM, Wells C, Chua R. The role of cutaneous receptors in the foot. Adv Exp Med Biol, 2002; 508:111-7

Karadenizli ZI, Erkut O, Ramazanoglu N, Uzun S, Camliguney AF, Bozkurt S, Tiryaki C, Kucuk V, Sirmen B. Comparision of dynamic and static balance in adolescent handball and soccer players. Turk J Sport Exe, 2014; 16: 47-54

Kavounoudias A, Roll R, Roll JP. Foot sole and ankle muscle inputs contribute jointly to human erect posture regulation. J Physiol, 2001; 532: 869-78

(c) Editorial Committee of Journal of Human Kinetics 
Kavounoudias A, Roll R, Roll JP. Specific whole-body shifts induced by frequency modulated vibrations of human plantar soles. Neurosci Lett, 1999; 266: 181-4

Kavounoudias A, Roll R, Roll JP. The plantar sole is a dynamometric map for human balance control. Neuroreport, 1998; 9: 3247-52

Kennedy PM, Inglis JT. Distribution and behaviour of glabrous receptors in the human foot sole. J Physiol, 2002; 538: 995-1002

Ku PX, Abu Osman NA, Yusof A, Wan Abas WA. The effect on human balance of standing with toe-extension. Plos One, 2012; 7: e41539

Marques MC, Gonzalez-Badillo JJ. In-season resistance training and detraining in professional team handball players. J Strength Cond Res, 2006; 20: 563-71

Martins HS, Lüdtke DD, Araùjo JC, Cidral-Filho FJ, Salgado ASI, Viseux F, Martins DF. Effects of core strengthening on balance in university judo athletes. Doi.org/10.1016/j.jbmt.2019.05.009

Maszczyk A, Gołaś A, Pietraszewski P, Kowalczyk M, Cięszczyk P, Kochanowicz A, Smółka W, Zając A. Neurofeedback for the enhancement of dynamic balance of judokas. Biol. Sport,2018; 35: 99-102

McGuine Ta, Greene JJ, Best T, Leverson G. Balance as a predictor of ankle injuries in high school basketball players. Clin J Sport Med, 2000; 10: 239-44

Mononen K, Konttinen N, Viitasalo J, Era P. relationships between postural balance, rifle stability and shooting accuracy among novice rifle shooters. Scand J Med Sci Sports, 2007; 17: 180-5

Okai LA, Kohn AF. Quantifying the contributions of the flexor digitorum brevis muscle on postural stability. Motor Control, 2015; 19: 161-172

Paillard T, Costes-Salon C, Lafont C, Dupui P. Are there differences in postural regulation according to the level of competition in judoists? Br J Sports Med, 2002; 36: 304-5

Paillard T, Noé F, Rivière T, Marion V, Montoya R, Dupui P. postural performance and strategy in the unipedal stance of soccer players at different levels of competition. J Athl Train, 2006; 41: 172-6

Paillard T, Noé F. Effect of expertise and visual contribution on postural control in soccer. Scand J Med Sci Sports, 2006; 16: 345-8

Palmieri RM, Ingersoll CD, Cordova ML, Kinzey SJ, Stone MB, Krause BA. The effect of a stimulated knee joint effusion on postural control in healthy subjects. Arch Phys Med Rehabil, 2003; 84: 1076-9

Palmieri RM, Ingersoll CD, Stone MB, Krause BA. Centre of pressure parameters used in the assessment of postural control. J Sports Rehabil, 2002; 11: 51-66

Patel M, Magnusson M, Kristinsdottir E, Fransson PA. The contribution of mechanoreceptive sensation on stability and adaptation in the young and elderly. Eur J Appl Physiol, 2009; 105: 167-73

Pyykko I, Jantti P, Aalto H. Postural control in elderly subjects. Age Ageing, 1990; 19: 215-21

Rannou F, Prioux J, Zouhal H, Gratas-Delamarche A, Delamarche P. Physiological profile of handball players. J Sports Med Phys Fitness, 2001; 41: 349-53

Raymakers JA, Samson MM, Verhaar HJJ. The assessment of body sway and the choice of the stability parameter(s). Gait Posture, 2005; 21: 48-58

Ricotti L. Static and dynamic balance in young athletes. J Hum Sport Exerc, 2011; 6: 616-28

Roll R, Kavounoudias A, Roll JP. Cutaneous afferents from human plantar sole contribute to body posture awareness. Neurorepor, 2002; 13: 1957-61

Ross SE, Guskiewicz KM. Examination of static and dynamic postural stability in individuals with functionally stable and unstable ankles. Clin J Sport Med, 2004; 14: 332-8

Salehzadeh K, Karimiasl A, Borna S, Shirmohammadzadeh M. The effects of 8-week plyometric and combinational trainings on dynamic balance of teenage handball players. J Basic Appl Sci Res, 2011; 1: 3316-21 
Schieppati M, Hugon M, Grasso M, Nardone A, Galante M. The limits of equilibrium in young and elderly normal subjects and in parkinsonians. Electroencephalogr Clin Neurophysiol, 1994; 93: 286-98

Soderman K, Alfredson H, Pietila T, Werner S. Risk factors for leg injuries in female soccer players: a prospective investigation during one out-door season. Knee Surg sports Traumatol Arthrosc, 2001; 9: 31321

Stal F, Fransson PA, Magnusson M, Karlberg M. Effects of hypothermic anaesthesia of the feet on vibrationinduced body sway and adaptation. J Vestib Res, 2003; 13: 39-52

Strzalkowski NDJ, Peters RM, Inglis JT, Bent LR. Cutaneous afferent innervation of the human foot sole: what can we learn from single-unit recordings? J Neurophysiol, 2018; 120: 1233-46

Tanaka T, Hashimoto N, Nakata M, Ito T, Ino S, Ifukube T. Analysis of toe pressures under the foot while dynamic standing on one foot in healthy subjects. J Orthop Sports Phys Ther, 1996a; 23: 188-93

Tanaka T, Noriyasu S, Ino S, Ifukube T, Nakata M. Objective method to determine the contribution of the great toe to standing balance and preliminary observations of age-related effects. IEEE Trans Rehabil Eng, 1996b; 4: 84-90

Tortolero X, Masani K, Maluly C, Popovic MR. body movement induced by electrical stimulation of toe muscles during standing. Artif Organs, 2008; 32: 5-12

Vijayaragavan R, Perumal V. Effect of balance exercise program on static balance of male handball players at school level. Int J Phys Educ Sports Health, 2016; 3: 285-8

Viseux F, Barbier F, Villeneuve P, Lemaire A, Charpentier P, Leteneur S. Low additional thickness under the toes could change upright balance of healthy subjects. Neurophysiol Clin, 2018; 48: 397-400

Viseux F, Lemaire A, Barbier F, Charpentier P, Leteneur S, Villeneuve P. How can the stimulation of plantar cutaneous receptors improve postural control? Review and clinical commentary. Neurophysiol Clin, 2019; 49: 263-8

Wagner H, Finkenzeller T, Wurth S, von Duvillard SP. Individual and team performance in team-handball: a review. J Sports Sci Med, 2014; 13: 808-16

Wang HK, Chen CH, Shiang TY, Jan MH, Lin KH. Risk-factor analysis of high school basketball-players ankle injuries: a prospective controlled cohort study evaluating postural sway, ankle strength, and flexibility. Arch Phys Med Rehabil, 2006; 87: 821-5

Winter DA, Patla AE, Frank JS. Assessment of balance control in humans. Med Prog Technol, 1990; 16: 31-51

Witchalls JB, Newman P, Waddington G, Adams R, Blanch P. Functional performance deficits associated with ligamentous instability at the ankle. J Sci Med Sport, 2013; 16: 89-93

Wright WG, Ivanenko YP, Gurfinkel VS. Foot anatomy specialization for postural sensation and control, $J$ Neurophysiol, 2012; 107: 1513-21

Zemkova E. Sport-specific balance. Sports Med, 2014; 44: 579-90

\section{Corresponding author:}

\section{Frederic Viseux}

Laboratoire d'Automatique, de Mécanique et d'Informatique industrielles et Humaine (LAMIH) - UMR CNRS 8201, Université Polytechnique des Hauts-de-France (UPHF), F-59313 Valenciennes, France.

Phone Number: +33 (0)652543541

E-mail: viseux-f@ch-valenciennes.fr 